\title{
Teachers' Construction of Learning Environments for \\ Conditional Probability and Independence
}

\author{
Randall E. Groth \\ Salisbury University
}

\begin{abstract}
Although literature on challenges to students' learning of data analysis and probability has steadily accumulated over the past few decades, research on challenges encountered in teaching the content area is in its beginning stages. The present study aims to help build this area of research by identifying some knowledge elements necessary for teaching conditional probability and independence. Artifacts of classroom practice, including written plans and lesson video, were used to identify challenges encountered by teachers in establishing productive learning environments for students first learning the concepts. It is proposed that enhanced common and specialized content knowledge may help teachers address the challenges identified. Some salient aspects include knowledge of: distinctions among major concepts, data displays with pedagogical value, and the roles of fractions and combinatorial ideas in the psychology of learning conditional probability and independence. The discussion of these and other relevant knowledge aspects is drawn upon to propose potentially productive directions for teacher education efforts and future research.
\end{abstract}

Keywords: conditional probability; statistical independence; learning environments; mathematical knowledge for teaching

In its report entitled The Mathematical Preparation of Teachers, the Conference Board of the Mathematical Sciences (2001) observed,

Of all the mathematical topics now appearing in middle grades curricula, teachers are least prepared to teach statistics and probability. Many prospective teachers have not encountered the fundamental ideas of modern statistics in their own K-12 mathematics courses...Even those who have had a statistics course probably have not seen material appropriate for inclusion in middle grades curricula. (p. 114)

This state of affairs makes it difficult for teachers to understand and implement innovative middle school ${ }^{1}$ curricula that include probability and data analysis (e.g., Lappan, Fey, Fitzgerald, Friel, \& Phillips, 1997; National Center for Research in Mathematical Sciences Education \& Freudenthal Institute, 1997-1998). It also makes acting upon recent influential curricular recommendations for teaching data analysis and probability (e.g., Franklin et al., 2007; NCTM, 2000) problematic for teachers.

Prominent curriculum documents have recommended that students study ideas related to conditional probability before leaving grade 12. NCTM (2000) recommended that students in grades 9-12 should "understand the concepts of conditional probability and independent events" (p. 324). The Pre-K-12 Guidelines for Assessment and Instruction in Statistics Education (GAISE) (Franklin et al., 2007) also recommended that students understand the concept of independence before leaving high school. Both documents emphasized the 
importance of independence to making various statistical claims, and how the assumption that events are independent when they actually are not can lead to flawed conclusions.

Teacher education can serve as a link toward ensuring that the new curricula and curricular recommendations actually influence the curricula enacted in classrooms. Although literature on challenges to students' learning of probability has steadily accumulated over the past few decades (Jones, Langrall, \& Mooney, 2007), research on challenges encountered in teaching the content area is in its beginning stages. Stohl (2005) stated that although a fair amount of research with the potential to inform teacher education has been conducted in the area of data analysis, such research is not as prevalent in the area of probability. Jones, Langrall, and Mooney affirmed Stohl's assessment, pointing out that there is just some research emerging in the area (e.g., Watson, 1997, 2001). If teachers are to create environments that foster students' probabilistic understanding, it is important for researchers to engage in increased dialogue about how this can be accomplished. In particular, to move the field forward, it is important to move beyond the observation that probability is a difficult subject for teachers toward drawing upon empirical data to identify productive directions for teacher education and further research.

\section{Purpose of the Study}

The present study aims to contribute to dialogue about the theory and practice of teacher education in the specific area of preparing middle school teachers to teach conditional probability and independence. Toward that end, the central research question is, "What challenges do middle school teachers encounter in constructing learning environments for conditional probability and independence?" The research question is based on the premise that a careful and systematic examination of teachers' difficulties in teaching the topic will help support critical dialogue about teacher education. The intent is not to produce a "deficit model" profile of teachers, but to help identify salient challenges teachers face in creating effective classroom learning environments for the concepts, and to propose strategies for helping teachers overcome the challenges.

\section{Theoretical Framework}

Because the central research question for the study concerned the identification of challenges teachers face in constructing effective learning environments, a theoretical characterization of such environments was necessary. One prominent perspective on the nature of effective learning environments was offered by the National Research Council (NRC) (2000). It was used as the primary analytic lens for the present study because of its attention to multiple functions teachers must perform to facilitate student learning. This section offers a general description of the NRC model followed by observations about its

pertinence to the specific case of learning environments for conditional probability and independence. 


\section{General Model of Effective Learning Environments}

In synthesizing existing cognitive science literature, NRC (2000) characterized effective learning environments as knowledge-centered, community-centered, assessment-centered, and learner-centered. These four elements can be described briefly in the following manner:

- Knowledge-centered environments are dedicated to helping students develop formal knowledge of a discipline and the ability to transfer learning to outside-of-school contexts. In order to attain these goals, students need to learn with understanding rather than by rote.

- Community-centered environments are those in which discursive norms supportive of student learning exist. The communities outside of the school setting which influence student learning are also acknowledged and drawn upon.

- Assessment-centered environments are characterized by the use of formative assessments to guide the path instruction should take. Not only do teachers assess students, but they also engage students in metacognitive activity to self-assess their own understanding of content.

- Learner-centered environments are designed to build upon the previous knowledge and experiences of students. It is acknowledged that students do not arrive in the classroom as "blank slates," but that they bring various ideas to the classroom that can either facilitate or impede learning.

Examining the extent to which teachers are able to create learning environments that reflect this model can help frame challenges to teaching. In turn, aspects of knowledge relevant to overcoming the challenges can be identified.

The NRC (2000) framework provided a comprehensive frame for analysis in the present study because of its focus upon multiple, overlapping elements of effective classrooms. The four primary model elements (learner, knowledge, assessment, and community centeredness) are not mutually exclusive. For example, an activity that is designed to reveal and challenge students' misconceptions about a central concept in a given discipline through classroom discourse could be said to exemplify each of the four elements to an extent. In the present study, phenomena reflecting multiple elements of the NRC model were generally discussed in terms of the element they most strongly exemplified. This was done primarily for the sake of convenience and succinctness, and should not be considered an attempt to sort the challenges that teachers face into discrete categories or bins.

\section{Effective Learning Environments for Conditional Probability and Independence}

Existing research literature from mathematics and statistics education can help operationalize the NRC (2000) model to the specific case of learning conditional probability and independence. Literature pertinent to each of the four main elements of the model is considered below.

Knowledge-centered focus. When scaffolding students' learning toward the acquisition of formal disciplinary knowledge, it is important to recognize that initially, students may use their own invented strategies to solve problems. In the case of conditional probability and 
independence, the research of Tarr and Jones (1997) showed that some students can make comparisons between the likelihood of different events by reasoning from sample space composition for each event (e.g., reasoning that in a "without replacement" situation, the outcome of the first event changes the sample space for the second event, making the second event either more or less likely to occur). Eventually, with appropriate support from teachers, students can use the formal strategy of assigning numerical probabilities to events to make precise comparisons.

Bright, Frierson, Tarr, and Thomas (2003) provided a specific example of the type of support that can be used to help middle school students develop the formal concepts of conditional probability and independence. They used a candy jar with three blue and three yellow candies, posing a situation where an individual takes one candy out without looking, eats it, and then draws a second. The probability that the second is yellow depends upon the color of the first, so in this situation, the events "yellow on the first draw" and "yellow on the second draw" are dependent. This can be contrasted with a situation in which an individual takes a candy out of the jar without looking, replaces it, and then draws another at random. The second situation provides an example of independent events. By contrasting the "without replacement" and "with replacement" situations, middle school students can begin to understand the distinction between dependent and independent events. In "without replacement" situations, the sample space changes from one event to the next, whereas it is unchanged in "with replacement" situations. Focusing on sample space composition in each type of situation can help middle school students begin to distinguish between dependent and independent events (Tarr, 1997; Tarr \& Lannin, 2005).

A knowledge-centered focus also implies bearing in mind that students will encounter conditional probability in outside-of-school social contexts. Students need to be able to transfer knowledge from "choosing balls out of urns" situations to understanding conditional probability and independence in everyday situations like those that are often analyzed with two-way tables of data. To illustrate conditional probability, for example, teachers may ask students to use data to estimate the probability that a baseball player will get a hit given different conditions (e.g., playing on the road, playing in April, etc.) (Watson, 1995). Teachers with an eye toward designing knowledge-centered environments may choose to include such problems in lessons so that students develop a broader understanding of settings in which the concepts of conditional probability and independence are applicable (Watson \& Moritz, 2002).

Community-centered environments. Of all the communities that influence learning, the classroom community is generally the one over which teachers generally exert the most influence. It is important for teachers to work to establish classroom norms that support highlevel thinking and problem solving. When students are engaged in inquiry-oriented activities, unsystematic exploration and strictly procedural activity are to be avoided (Henningsen \& Stein, 1997). Unsystematic exploration occurs when teachers provide little guidance to help support students' learning. In such cases, students' conversations tend to focus on asking what they are required to do or on mathematically irrelevant issues. Strictly procedural activity occurs when students are given a precise sequence of steps that must be followed for all tasks. At times, tasks that initially allow for a degree of exploration can degenerate to the 
point of fostering show-and-tell patterns of classroom discourse as students exert pressure on teachers to provide more direction for their problem solving activities (Henningsen \& Stein, 1997). Teachers can maintain high levels of cognitive demand in inquiry-oriented activities by building on students' previous knowledge, providing relevant scaffolding, allowing enough time for students to work, and pressing students to explain their thinking (Henningsen \& Stein, 1997).

Although the classroom community is generally the one over which the teacher has the most influence, they should also seek to understand the effects of communities outside the classroom upon students' learning. In one study, for example, Amir and Williams (1999) found that children's religious beliefs caused them to doubt that some events were attributable to chance due to belief that God controls the outcome of certain events. They found that other students brought superstitions about games of chance and other random events from their cultures outside of school to the classroom. Hence, teachers need to understand and acknowledge that cultural influences from beyond the classroom can influence students' probabilistic learning along with the culture of the classroom.

Assessment-centered environments. In assessment-centered environments, teachers' assessments are to be both summative and formative. Summative assessments aim to accurately measure the acquisition of learning. Ideally, such assessments should focus on understanding, and not exclusively on memorization of procedures or facts. Formative assessments are those which give teachers information about students' understanding that is used to help chart the path that instruction should take. The teaching experiment methodology (Steffe \& Thompson, 2000) provides a paradigm example of how formative assessment can be used to guide instruction, since data are carefully gathered each day as a basis for vetting and improving the next day's learning activities. As teachers evaluate the quality of their own teaching through formative assessment techniques, they can also help students engage in the metacognitive process of self-assessment. Students should determine whether or not their solutions to problems make sense, since metacognition is vital to independent problem solving (Schoenfeld, 1992).

Learner-centered environments. In the case of teaching conditional probability, the literature bears out the importance of taking learner characteristics into account in designing instruction. Probability appears to be one of the most difficult mathematical subjects to learn, as numerous misconceptions have been cataloged by researchers (Shaughnessy, 1992). In the case of conditional probability, one such misconception is that "mutually exclusive events" are the same as "independent events" (Kelly \& Zwiers, 1986). Another misconception is that all conditional probability situations must involve sequential events (Ancker, 2006). Students might also incorrectly equate the concepts of conditionality and causality (Falk, 1986). To build learner-centered environments, teachers must become aware of and address such aspects of students' knowledge and beliefs.

Research suggests resolutions to some of the learner-related dilemmas involved in teaching conditional probability and independence. Watson and Moritz (2002), for instance, found that middle school students were more successful with conditional probability tasks when asked for frequencies rather than probabilities. They compared students' performance on two tasks: 
Q3. Please estimate:

(a) Out of 100 men, how many are left-handed.

(b) Out of 100 left-handed adults, how many are men.

Q4. Please estimate:

(a) The probability that a woman is a school teacher.

(b) The probability that a school teacher is a woman. (Watson \& Moritz, 2002, p. 66).

When answering Q3, students were less likely to say that both events had the same probability (i.e., they were less likely to make the mistake of assuming that $P(A \mid B)=P(B \mid A)$ for the given situation). Teachers can utilize this information by having students examine and reason from data before working with probability statements (Shaughnessy, 2003). As teachers help students understand content by taking students' existing knowledge, skills, and beliefs into account, the potential exists to improve students' attitudes toward the subject, since teaching for understanding has been shown to be an effective student motivator (Stipek, Salmon, Givvin, Kazemi, Saxe, \& MacGyvers, 1998).

\section{Summary}

The four elements of effective learning environments, taken together, provided a frame of reference for studying teacher-constructed learning environments for conditional probability and independence. The extent to which teachers' practices exemplified the learner-centered, knowledge-centered, assessment-centered, and community-centered paradigms facilitated the identification of instructional challenges they faced.

\section{Method}

The present study was largely exploratory in nature, as research on probability teacher education is an emerging field of study (Stohl, 2005). Small-scale, qualitative, exploratory studies are particularly helpful and appropriate when few domain-specific frameworks exist for understanding a phenomenon of interest (Scheaffer \& Smith, 2007). Although the design and number of participants involved in the present study do not permit for statistical generalization, the findings do help shape the emerging field of probability teacher education by exposing potentially important variables in need of attention and investigation.

\section{Background}

The study arose from work with middle school teachers during a professional development project in the Mid-Atlantic U.S. Teachers in the project were asked to write lessons for concepts they found difficult to teach. They were required to use the four-column format described by Curcio (2002). The four columns were to contain the procedural steps to be carried out in completing the lesson, the main learning activities, students' anticipated difficulties with the lesson, and remarks on teaching. This format was used to prompt teachers to design instructional plans that would be responsive to students' learning needs, and to provide the researcher insight on the teachers' knowledge of students and pedagogy. Teachers then implemented the lessons and had them videotaped by another teacher in their 
school building. The videotapes were then later viewed and critiqued during a large-group professional development session during the summer following the lessons.

\section{Participants}

The present study focused upon three seventh-grade teachers who participated in the professional development project and chose to work on improving their teaching of conditional probability and independence. They will hereafter be referred to as Mark, Julie, and Stephanie (pseudonyms). The three teachers worked in the same school district, and they reported collaborating on writing lessons on several occasions. Despite their collaborations on teaching conditional probability and independence, they still identified these as particularly difficult concepts to teach. The specific standards from the state curriculum they sought to address more effectively in their lessons were:

- "Describe the difference between dependent and independent events"

- "Determine the probability of an event comprised of no more than 2 independent events"

- "Determine the probability of a second event that is dependent on the first event of equally likely outcomes" (Maryland State Department of Education, 2004, p. 11).

Because the three teachers identified these as difficult standards to address, their classroom teaching practices were considered to be potentially rich sources of information about extant challenges in creating learning environments for conditional probability and independence.

\section{Data Gathering}

Mark, Julie, and Stephanie produced multiple data sources for analysis. Data sources included: a written four-column lesson from each teacher, worksheets and handouts to accompany the lessons, PowerPoint presentations used during the lessons, email correspondence with the researcher regarding the lessons, video of the implemented lessons, and field notes recording teachers' verbal reflections about the strengths and weaknesses of the lessons during the large-group summer professional development session. These materials, along with lesson video transcripts, the state curriculum documents the teachers were responsible for following, and the researcher's personal notes on the written and videotaped lessons were all retained for analysis.

\section{Data Analysis}

The NRC (2000) framework was used as the starting point for identifying challenges related to teaching conditional probability and independence within the data gathered during the study. As challenges related to attaining one or more of the elements of the NRC model were identified, they were clustered into categories (Miles \& Huberman, 1994), and the categories were refined iteratively using a concept map visual display as a tool (Maxwell, 2005). Throughout the clustering process, the fidelity of each cluster to the empirical data was continuously re-examined. The final form of the concept map visual display and the clusters of related challenges it contained are shown in Figure 1. 


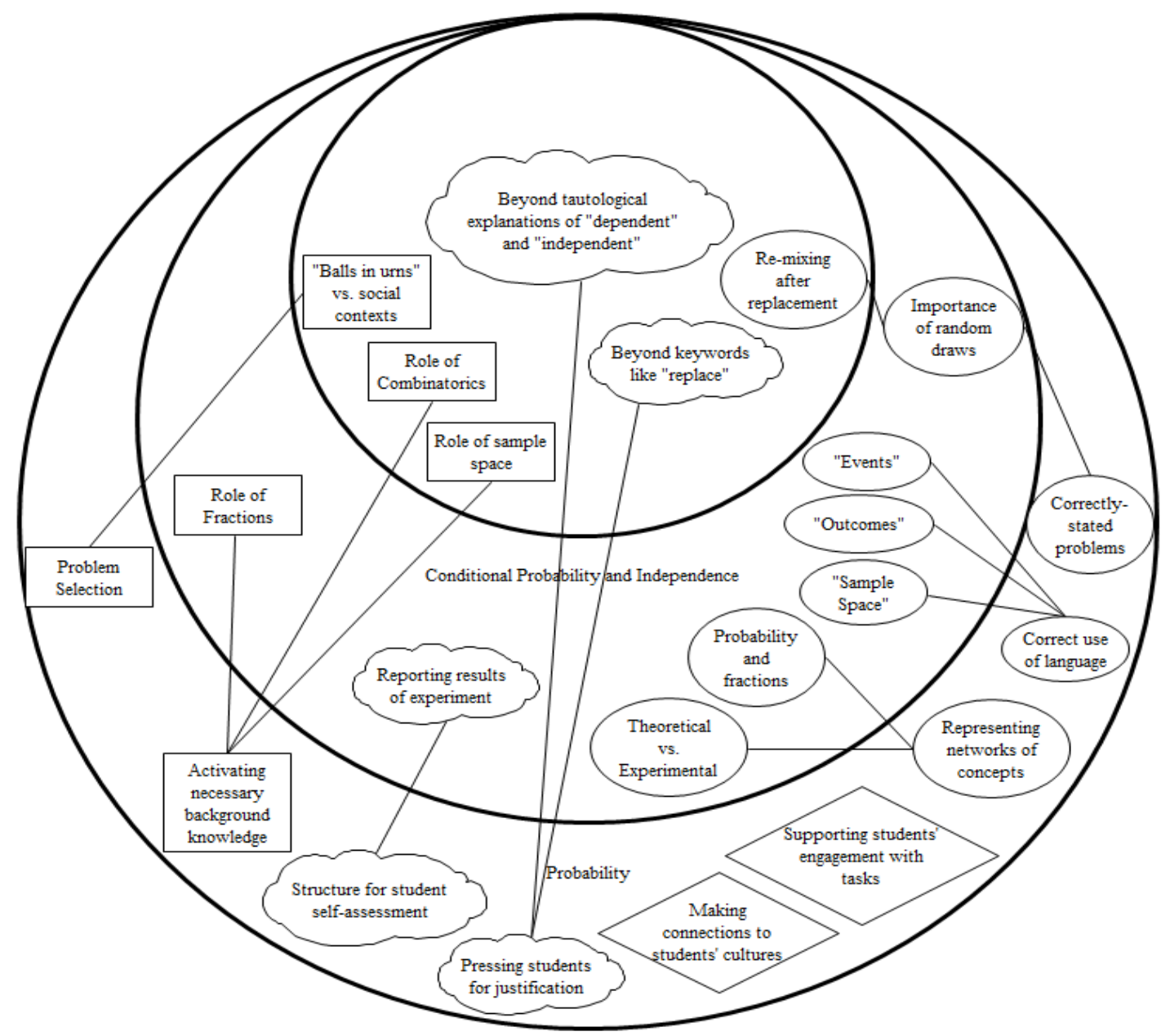

Mathematics

Figure 1. Visual display used to facilitate qualitative analysis of data.

Note. Related challenges are clustered together with line segments, and clusters are situated within the categories of mathematics, probability, and conditional probability and independence.

Key:

Knowledge-centered environment issue

$>$ Community-centered environment issue

Assessment-centered environment issue

$\square$ Learner-centered environment issue

In addition to providing a visual organizer for mapping clusters of theoretically significant challenges and checking conclusions drawn against the empirical data, Figure 1 provided the starting point for writing descriptive narratives about challenges faced in teaching conditional probability and independence. The writing process itself provided another check on the fidelity between the data and how they were represented in the research (Glesne, 1999; Richardson \& St. Pierre, 2005), as findings were contextualized and validated by returning once again to the empirical data as narratives were written. The finalized descriptive narratives are presented in the next section of this report. 


\section{Results}

Mark, Stephanie, and Julie exhibited similarities and differences in the manner they planned to teach conditional probability and independence. This section begins with a broad outline of the written lesson plan each teacher submitted. The broad outlines are followed by descriptive narratives about the theoretically significant challenges (in terms of NRC, 2000) that arose for each teacher in designing and enacting classroom learning environments for conditional probability and independence.

\section{Mark's Written Lesson}

Mark's written lesson began with a "math maintenance" activity. The five problems in the activity included an array of topics: adding rational numbers, solving equations, constructing a box-and-whisker plot, interpreting a scatterplot, and calculating the probability of a compound event. As implied by the title of the activity, the problems were intended to remind students of previously-studied mathematics. "Math maintenance" was done every day on the theory; it would help students retain the mathematics needed for the state's end-of-year standardized tests.

After completing the math maintenance activity, students were to play a game that involved drawing colored chips from a bag. Mark described the game in the following manner:

Students will be paired with a bag of colored chips. Each bag will contain 3 blue chips and 1 purple chip. The object of the game is to pick two blue chips in a row. Each time a player picks two in a row they will receive a point. One player gets to pick a chip out of the bag, put it back in the bag and pick another chip. The second player will pick a chip out of the bag, leave it out of the bag and pick another chip. Students will go twenty rounds to see who has more points. Students will keep a tally chart to see who won more games. An example of the tally chart will be on the document camera for students.

Mark planned to follow the game by asking students which player won more often, and why.

During the final part of the lesson, students were to complete a worksheet. The worksheet had some situations involving dependent events, and others involving independent events. Students were to choose an option (independent or dependent) by comparing the situations on the worksheet to the game played earlier in the lesson. Mark then planned to formally introduce the terms "independent" and "dependent" and discuss how to distinguish between the two by means of notes given to students on a PowerPoint presentation. After the teacher presentation, students were to complete additional problems that required application of the concepts learned in the lesson to new situations. A brief written assessment at the end of the lesson required students to classify situations as involving either dependent or independent events. 


\section{Stephanie's Written Lesson}

Stephanie's lesson plan began with having students complete the same "math maintenance" exercise as Mark's class. Immediately after the math maintenance activity, she planned to give students three "warm-up" problems she believed to be pertinent to the topic of probability. The first warm-up problem involved counting the number of ways an individual could order breakfast given that she could select one of three main dishes, one of two drinks, and one of three fruits. Mark ultimately built a similar problem into the beginning of his lesson. The second warm-up problem asked for the probability of drawing a "king" from a set of cards. The third and final warm-up problem asked for the probability of getting "heads" on a coin toss and landing on "yellow" on a spinner with four colored sections.

The main activity planned for the day was a card-sorting exercise. Students were to be given some cards with situations involving independent events printed on them, and others with dependent events. Students were to read the cards, discuss similarities and differences among them in small groups, and sort the cards into two piles. After sorting the cards, the students, with the assistance of the teacher, were to solve the problems printed on them. The lesson was to end with the teacher introducing the words "dependent" and "independent" in relation to the problems that were done. A written assessment at the end of the lesson required students to distinguish between independent and dependent events, and also to calculate probability in one situation involving dependent events and one involving independent events.

\section{Julie's Written Lesson}

The sequence of events in Julie's lesson mirrored the sequence in Stephanie's. The two teachers used the same handouts and problems for each phase of the lesson. The only discernible difference between the two initial written lesson plans was that Julie planned to have materials ready for students who finished well before the rest of the class. She described these materials as, "Various worksheets and/or activities available in the classroom that provide reinforcement for concepts previously learned, problem solving skills, and/or logical reasoning." Although Julie's written lesson plan was virtually the same as Stephanie's, some substantive differences between the two teachers' learning environments were apparent during the actual implementation of the lessons, as described below.

\section{Building Knowledge-Centered Learning Environments}

Stating problems correctly. Correctly-stated problems can be considered one of the cornerstones of knowledge-centered learning environments. Often in probability problems, one of the vital elements to state is that random selection or random number generation takes place. Random number generators and selection mechanisms vary by situation (e.g., dice, blind draws, tables of random numbers). If such generators or mechanisms are not specified, students are left to make a potentially wide range of assumptions about the situation.

All three teachers posed problems that required random number generators or random selection. In their lessons, however, the teachers did not explicitly state that the mechanisms used in their problems produced random results. In some cases, randomization seemed to be assumed, as in the following problem used by both Stephanie and Julie: "What is the 
probability of rolling a 1 on a six-sided die and landing on a green with a spinner that has 2 blue, 3 red and 5 green sections?" The implicit assumption seemed to be that the die and the spinner were random mechanisms. Such an assumption might be reasonable if the teachers' classes had developed a taken-as-shared understanding that such mechanisms produce random results unless otherwise specified.

In other problems the teachers posed, however, the assumption that random number generation or random selection occurred was not reasonable because of problem context. Consider the following problem that Stephanie used in her lesson:

If you are team captain of your kick ball team, there are 20 players, 12 are your friends and 8 are not, what is the probability of selecting a friend to be on your team after you selected the first player that is not your friend?

Mark and Julie also used the kickball problem, phrased slightly differently, but still not attending to the issue of random selection. In the kickball problem, it would be unreasonable to assume that team members are chosen at random, because selection of a team member usually involves a deliberate, purposeful choice. Given that random selection was not specified, there was no obvious answer to the question. Whether or not someone would select a player that is a "friend" could depend on a variety of unspecified contextual factors. Purposefully posing such an ambiguous question did not appear to be the teachers' aim, since in the lesson videos it appeared that they wanted students to treat the kickball problem as just another "without replacement" situation.

Another layer of randomization is pertinent to "with replacement" probability situations: In some contexts, it is important to specify that re-mixing takes place after an item is replaced. Discussion of this point was missing from all three teachers' written and implemented lessons. Moreover, the game Mark had his students play involved having a player draw a chip from a bag, replace it, and draw another. In a whole-class demonstration of the game, he had a student in the front of the room go through this sequence of events. When the student replaced the chip, Mark did not shake the chips in the bag to re-mix them or acknowledge this as an important part of the game. Because the goal of the game was to select two blue chips in a row, students trying to win the game could essentially replace a blue chip they had drawn and then attempt to go back to the location they placed the chip to draw it again. Later in the lesson, one student noticed this apparent shortcut to winning the game, stating during class discussion, "Since I drew and then I had to put it [the blue chip] back, I had a greater chance of picking that one back out." Hence, the missing demonstration and discussion of re-mixing appeared to work against the objective of helping students understand how "with replacement" situations illustrate conditional probability.

Use of language. Use of probabilistic language also posed a barrier to the establishment of knowledge-centered learning environments. Language use is pertinent to establishing a knowledge-centered learning environment because part of the teacher's role is to help students work toward using words and phrases in accord with the conventions of the discipline under study. Incorrect or awkward uses of language may misrepresent disciplinary conventions. 
Mark used the word "outcomes" in a somewhat awkward way in posing a problem. $\mathrm{He}$ stated at one point in the video of his implemented lesson,

For dinner last night, I had a choice between a Caesar and tossed salad. I also had to choose my sauce for my spaghetti. My choices were marinara and alfredo. We also had 4 dessert options to choose from. How many outcomes did I have for dinner last night?

Presumably, Mark had just one "outcome" for dinner, unless he ordered dinner multiple times. From the context of the lesson, it appeared that he actually meant to ask, "How many different ways could I have ordered dinner last night?" since he engaged students in the process of formulating an answer to that question.

Stephanie and Julie had some imprecision in their use of the term "sample space." The instructions on a worksheet that Stephanie and Julie wrote together and subsequently gave to their students stated, "Determine the sample space using the Fundamental Counting Principle." The problem students were to solve was much like Mark's example of choosing a salad, sauce, and dessert for dinner - Stephanie and Julie just used the context of choices for parts of breakfast instead. A more precise set of directions would have asked students for the number of elements in the sample space, since this is what the teachers wanted students to do in the context of the lesson, rather than to specify all the elements in the sample space.

Some of Mark's uses of the term "event" were also problematic. On a PowerPoint slide he presented to his class, he defined "independent events" and "dependent events" in the following manner,

- Independent events - the probability of two events when the second event does not depend on the first event.

- Dependent events - the probability of two events when the second event does depend on the first event.

In addition to being somewhat tautological, the definitions defined an "event" as a "probability." The definitions also appeared to confuse the ideas of conditionality and causality, and implied that independent or dependent events must occur in sequence.

Representing networks of concepts. Although teachers' use of language is one element of knowledge-centered environments, that issue may be secondary to the ways in which teachers represent the networks that exist among concepts. In teaching probability, fractions, theoretical probability, and experimental probability can all become pertinent.

One of Mark's attempts to help students distinguish between independent and dependent events involved a fraction rule he had formulated. On one of the PowerPoint slides he showed in class, he wrote,

- Independent events - The denominators will be the same when you have the same events.

- Dependent events - The denominators will not be the same when you have the same events. 
These ideas appeared to be an attempt to give students a simple algorithm for determining if events are dependent or independent. Although the algorithm works in some cases, there are many cases in which it does not.

The concepts of theoretical and experimental probability also must be represented in relationship to one another when teachers take data-gathering approaches to helping students understand probability. Mark's lesson involved gathering data from trials of a game, but Julie and Stephanie did not have students gather data. Instead, they used the earlier-described cardsorting exercise as the main learning activity for the lesson. In reflecting on his lesson, Mark noted that the experimental results for the game, when he played it with his students, did not match what he expected theoretically. During his lesson, he attempted to address this issue with the following explanation to students:

Even though it's not by much, player 1 has a greater probability of winning than player $2 \ldots$ How many people that were player 2 won? [some students raise their hands]. Because it wasn't that much, player 2 could still possibly win, because the probability between these two is not as great as it should - I mean, as we initially thought it was.

Although the statement drew a distinction between theoretical and experimental probability, it also implied that the experimental results would have to match the theoretical results if the theoretical probabilities for each player winning had been further apart to begin with.

\section{Building Community-Centered Learning Environments}

Classroom culture. Henningsen and Stein (1997) identified "decline into using procedures without connections to concepts, meaning, and understanding" and "decline into unsystematic exploration" as ways in which learning environments can break down in terms of students' engagement with the tasks they are given. Instances of both phenomena were apparent in the lesson video from Mark, Stephanie, and Julie.

Mark and Stephanie set up learning environments that involved "decline into using procedures without connections to concepts, meaning, and understanding." The conversations in both classrooms resembled the "funneling" pattern of classroom discourse described by Wood (1998). That is, both teachers asked questions in a manner intended to guide students toward a pre-determined end. The following excerpt from Stephanie's lesson is illustrative:

Stephanie: You're tossing a coin, no matter if you do it five times or a hundred times, are those independent or dependent events? Justin?

Justin: Dependent.

Stephanie: OK, so what changes? On a coin, if you flip it.

Justin: Nothing.

Stephanie: OK, so if nothing changes, what is it going to be?

Justin: Independent.

Stephanie: Independent. OK. 
The funneling interaction pattern leaves little room for students to devise their own solution strategies or to explain their thinking processes. Instead, the teacher essentially takes students along the path that he or she would have taken to solve the problem, rather than eliciting the path the student would have taken.

Julie's classroom environment involved "decline into unsystematic exploration." The verbal instructions that she gave students about the card-sorting task initiated the decline:

You have two different types of events in situations on those cards. Try to figure out in your group how to sort them into those two different types. So, read through the situations together, or pass them around, whatever you would like to do, and then work together to sort them into two types of events. And be ready to explain to everyone else how you decided to group them, OK, what it is that is different about your two types of events, or your two types of situations.

In reflecting on the lesson after it occurred, Julie noted that students devised categories based on surface-level features of the problems. She felt that students did not progress toward understanding the distinction between independent and dependent events. The lesson ended with the following exchange between Julie and one of her students:

Julie: $\quad$ OK, let's stop again. Here's what we need to do, because we only have about 2-3 minutes left. So here's what we're going to need to do. We're going to need to put the clips back on these [i.e., the cards with the problems on them]. And what we'll do tomorrow is we'll come back to this tomorrow with a little bit different information and a little bit different problems. I have another way that we can do this to see if you can find what you need. You know what I'm saying?

Student: Can't you just do it?

Julie: $\quad$ No, I'm not going to just tell you, I'm not going to just do it. Put the clip back on them, and put them back in the material thing.

Julie appeared to be uncertain about how to structure discourse to draw students' attention away from the surface-level features of problems toward their deeper structural characteristics.

Connecting to students' cultures outside the classroom. The funneling patterns of discourse in the classrooms of Mark and Julie limited the extent to which students' cultural beliefs were elicited - a key aspect of learning probability (Amir \& Williams, 1999). Of the two teachers, Mark had perhaps the best chance of eliciting such beliefs, since his lesson involved playing a game of chance. Such games provide potentially rich contexts for eliciting misconceptions, beliefs, or superstitions that may influence students' learning of probabilistic ideas. Because the classroom discourse pattern was predominantly focused on guiding students along the path of the teacher's thinking, there was little opportunity for such elicitation. The main factor working against elicitation of students' thinking in Julie's classroom was decline into unsystematic exploration. When students focused predominantly 
on probabilistically-irrelevant features of the problems she gave them, their prior cultural knowledge, beliefs, and attitudes relating to the subject matter remained untapped.

\section{Building Assessment-Centered Learning Environments}

Pressing students for justification. Although discourse patterns in the classrooms of all three teachers limited what they could learn about students' thinking, they did make attempts at systematic formative assessment. Julie was conscious of the number of students she called upon during class. When she heard from the same student on a number of different occasions, she explicitly asked for someone who hadn't spoken yet to answer a question. Julie did not, however, ask students to explain themselves when giving an answer. "How" and "why" questions were not used. Julie was only concerned with whether or not the students' answers were correct.

Mark and Stephanie did, however, regularly ask students several "how" and "why" questions after they gave answers. Stephanie would frequently ask one student to provide an answer and then ask another student to justify it. Both teachers asked for justification of correct as well as incorrect answers. One problem, however, with each teacher's approach to questioning was that students were limited to giving responses containing teacher-prescribed "keywords." Stephanie, for instance, told her students,

You're going to get a list of about $10-12$ probability problems, and you're going to rally with your partner to answer back and forth, independent/dependent, and your reason why. So you have to tell your partner, "I saw the word replace, I saw the word 'not putting it back,' 'sample space changes,' 'sample space doesn't change.'” There should be some pretty short explanations, because rallying goes pretty quick, back and forth.

Mark also expected brief explanations that focused on key words and phrases, at one point telling his class, "You just need a short explanation, you don't have to go crazy, just a short explanation." Short explanations that used teacher-prescribed key words and phrases limited the amount teachers could learn about students' thinking, since students tend to latch onto key words instead of trying to make sense of problems (Clement \& Bernhard, 2005).

A unique limitation of Mark's questioning was that he accepted somewhat tautological explanations when asking students to justify whether two events were dependent or independent. Exchanges like the following were common:

Mark: In a dependent event, the first, uh, the second event relies on the first event. What about independent events? Jessica?

Jessica: The events don't depend on each other...

Mark: Yes, the events don't depend on each other.

Such exchanges allowed students to latch onto surface-level linguistic features of the terms "dependent" and "independent" to produce responses that would satisfy the teacher. The deeper structural meanings students ascribed to the terms was unexplored in such instances. 
Establishing student self-assessment mechanisms. Student self-assessment is another component of assessment-centered mathematics classrooms. Of the three teachers, Mark made the clearest, although minimal, attempt to help students self-assess. He asked them to keep track of the number of times they won or lost the chip-drawing game included in his lesson. Students played the game in pairs, with one student being player 1 and the other being player 2. As noted earlier, the goal of the game was to draw two blue chips in a row. Player 1 drew with replacement and player 2 without. At the end of the lesson, Mark asked each pair of students which player won more often.

Although Mark asked students to reflect on the results of the game they played, the manner in which he had students record and report data was limited in its potential to foster student self-reflection. As he had students report their results, he did not pool the data into a larger display for the class. Instead, he seemed to expect students to commit all of the verbally-reported results to memory. In addition, the way he had students report results was limited in its potential to produce data that could be pooled into a class display that would help students understand the probabilistic ideas embedded in the activity. He asked each pair to report which player won more often, but did not ask how many times player 1 won in each pair and how many times player 2 won. If he would have had students report the data in this manner, it would have been possible to compile the class data into two aggregate distributions - one representing several "player 1" trials and another representing player 2 and then ask students to compare the features of the distributions. Students could then form conjectures, based on their experiences playing the game, about why the distributions took shape as they did.

\section{Building Learner-Centered Learning Environments}

Activating necessary background knowledge. Tarr (1997) demonstrated that drawing students' attention to sample space in "with" and "without replacement" situations helps them begin to distinguish between dependent and independent events. Students do not necessarily need to count all of the outcomes in the sample space, but they do need to recognize that its composition changes in "without replacement" situations. Research also indicates, perhaps somewhat surprisingly, that knowledge of fractions also is not a vital pre-requisite (Tarr \& Lannin, 2005). Students can make informal quantitative comparisons between the numbers of elements in sample spaces before using fractions to compute precise probabilities.

In the present study, all three teachers did use fractions extensively. Julie provided the most evidence that she considered knowledge of fractions to be pre-requisite to distinguishing between independent and dependent events. She spent approximately 15 minutes near the beginning of her lesson reviewing the idea that probabilities can be written as fractions, decimals, and percents. During that portion of class, she had students solve several problems and write their solutions in all three forms. Stephanie and Mark also spent some time near the beginning of class on having students represent probabilities with fractions. However, in each class, the time was limited to one brief "probability warm-up" problem. After the probability warm-up, Stephanie and Mark's attention to fractions was limited to having students make calculations of exact probabilities for some of the classroom problems. Students were not encouraged to describe and compare probabilities in informal, intuitive terms because 
fractions were the only valued means for making probability comparisons in the three classrooms.

Stephanie, Mark, and Julie also sequenced their lessons in a manner that portrayed combinatorial knowledge as pre-requisite to distinguishing between dependent and independent events. As noted earlier, they asked students to solve problems involving the total number of ways to order a meal given certain choices for each course of the meal. An excerpt from Mark's dialogue with his students near the outset of his lesson suggests why he considered combinatorial knowledge to be an essential pre-requisite:

Mark: How did we find sample space of a dependent event? Rachel?

Rachel: In an independent event, you use fundamental counting principle.

Mark: Very good. In an independent event, you use the fundamental counting principle. We have been using fundamental counting principle all throughout seventh grade. Dependent event, what did we do? Nathan?

Nathan: Permutation.

Mark: Good, permutation, and what was a permutation. Nathan, how do we solve permutations?

Nathan: You have a factorial.

Mark: Good, factorial. And what does a factorial mean, or how do you solve a factorial? How do you solve a factorial? Noah?

Noah: 5 times 4 times 3 times 2 times 1 .

Mark: Very good, so 5 factorial. And a factorial, Noah, is represented by what symbol?

Noah: Oh, um exclamation thing.

Mark: Very good, an exclamation point. So if we had five factorial, that would be five times four times three times two times one. There is another way to find a dependent event permutation, uh, not permutation, dependent event sample space. How do we do it the other way? Not a permutation? Jessica?

Jessica: Multiplication.

Mark: Good, it's a multiplication problem. And that multiplication problem's depending on how many things we're choosing and decreasing the number by one each time.

Several observations, beyond the earlier-mentioned language issues, can be made about the excerpt above. The substance of the conversation and its positioning in the flow of the lesson imply that counting the precise number of elements in sample spaces of "with replacement" and "without replacement" situations is necessary to distinguish between dependent and independent events. As noted earlier, research indicates that such precise counting is not necessary, because students can begin to understand the distinction by using informal comparisons. Another problematic issue is that this conversation was followed by problems in which students were told that choosing parts of a meal constituted independent events. As discussed earlier, it was not specified that the choice of each part was done randomly, and in most contexts, one would not make such choices at random. The choice of 
one part of a meal may well influence the choice of another part (e.g., someone may be more inclined to choose "bacon" as their meat for breakfast if they have already chosen "eggs" as their main dish). Therefore, activating learners' pre-requisite knowledge about situations involving deliberate choice is likely to interfere with helping them distinguish between dependent and independent events rather than helping them understand.

Problem selection. Effective learning environments help students transfer knowledge to outside-of-school contexts. In the case of conditional probability, Watson and Moritz (2002) noted that it is important for students to be able to transfer knowledge from countable situations (e.g., "balls in urns") to questions set in social contexts that may require contextual knowledge along with numerical data.

Problems set in social contexts were missing from the lesson plans of all three teachers. At least two factors appear to have contributed to this phenomenon. First, the teachers' lessons were structured primarily around helping students achieve near-transfer of knowledge rather than transfer to situations outside the classroom. The commitment to near transfer is evident from the teachers' earlier-discussed emphasis on having students use keywords to solve neatly-structured classroom problems. Such instruction prepares students to generate correct solutions to predictably-worded problems rather than preparing them to reason through more complicated situations. Another, perhaps even stronger, factor in the teachers' choice to avoid problems from social contexts was the state curriculum they were responsible for teaching. The curriculum had numerically-defined "assessment limits" specifying the types of questions to be included on the end-of-year tests students were required to take. For conditional probability and independence, the assessment limits essentially required only countable situations by making statements like, "Use no more than 5 dependent events with no more than 10 outcomes in the first event," and "Use a sample space of 36 to 60 outcomes." Situations from social contexts were not specified as part of the curriculum.

\section{Discussion}

Several of the challenges teachers faced in constructing learning environments for teaching conditional probability and independence can plausibly be traced to aspects of the teachers' knowledge in need of further development. Groth (2007), building on the work of Hill, Schilling, and Ball (2004), theorized that both common and specialized knowledge are necessary when teaching topics related to statistics and probability. Common content knowledge (CCK) is a type of subject matter knowledge that is not unique to the task of teaching. It involves competencies developed in conventional mathematics courses, such as computing accurately, making correct mathematical statements, and solving problems (Hill, Schilling, \& Ball, 2004). Specialized content knowledge (SCK) is a type of subject matter knowledge that allows teachers to provide understandable explanations, appraise students' methods for solving problems, and construct and evaluate multiple representations for concepts (Ball, Hill, \& Bass, 2005). Potential areas in need of improvement in the teachers' CCK and SCK that can be inferred from the descriptions of the challenges they encountered in constructing productive learning environments are summarized in Table 1. 
Table 1

Relationship between content knowledge categories and challenges in learning environment construction

$\begin{array}{ll}\text { Content Knowledge Category } & \begin{array}{l}\text { Related Challenges in Learning Environment } \\ \text { Construction }\end{array}\end{array}$

Common Content Knowledge (CCK)

Specialized Content Knowledge (SCK)
Correct use of the terms "outcome" and "sample space," and "event."

Distinguishing between independent and dependent events.

Distinguishing between experimental and theoretical probabilities.

Specifying re-mixing and random number generation in contexts where students plausibly expect them.

Facilitating "focusing" discourse, assessing student thinking, and encouraging authentic problem-solving that goes beyond use of keywords like "replace."

Pooling students' experimental results into an accessible class display.

Distinguishing between essential and non-essential prerequisite student knowledge of fractions and combinatorics in choosing and sequencing student tasks.

Many of the challenges associated with CCK listed in Table 1 could plausibly be addressed by enhancing the quality of conventional courses in introductory statistics. The Guidelines for Assessment and Instruction in Statistics Education (GAISE) college report (American Statistical Association, 2005) described strategies to help enhance introductory courses. Drawing upon the research literature, the GAISE college report recommended pedagogical strategies such as using real data, stressing conceptual understanding and not just knowledge of procedures, replacing lectures with active learning experiences, using technology for data analysis and conceptual development, and employing formative assessments. As these teaching and assessment strategies become more prevalent in collegelevel courses, prospective teachers are likely to benefit by developing stronger CCK. Along with developing CCK, prospective teachers can begin to experience teaching and assessment strategies that go beyond lecture, procedurally oriented instruction, and traditional summative assessments. Experiencing inquiry-oriented pedagogical strategies has been shown to help prospective teachers apply and adapt similar strategies on their own (Schwarz \& Gwekwerere, 2007). Hence, the type of introductory statistics course envisioned in the 
GAISE college report has potential to help teachers in establishing knowledge-centered, community-centered, and assessment-centered learning environments.

Despite the potential benefits of courses aligned with the GAISE college report, the findings of the present study suggest that its recommendations alone will not help prospective teachers develop all of the knowledge needed to design effective learning environments for conditional probability and independence. In particular, developing learner-centered

environments requires a degree of specialized content knowledge that is not the province of introductory courses aimed at the general college population. Prospective teachers need to know something of the psychological aspects of learning conditional probability and independence; knowing how middle school students generally learn probabilistic concepts allows teachers to perform work-related tasks like choosing data-pooling displays that are accessible to students, connecting problem contexts to middle school students' experiences, and understanding the essential and non-essential cognitive pre-requisites for learning concepts (Table 1). These aspects of specialized knowledge can be developed in a variety of ways, such as analyzing cases of classroom instruction (e.g., Russell, Schifter, \& Bastable, 2002), studying current curricular recommendations for the middle grades (e.g., NCTM, 2000; Franklin et al., 2007), and examining middle school curriculum materials (e.g., Lappan, Fey, Fitzgerald, Friel, \& Phillips, 1997) and technologies (e.g., Konold \& Miller, 2005) that are based upon research on students' learning.

\section{Conclusion}

Teachers require several aspects of CCK and SCK if they are to design effective learning environments for conditional probability and independence in the middle grades. The present study suggests that gaps in either of these aspects of the knowledge base for teaching can interfere with the classroom instruction students experience. Current recommendations for the content of college-level introductory statistics courses provide some guidance on how to better develop prospective teachers' CCK while also allowing them to experience learning in an inquiry-oriented setting. However, if teachers are to become more proficient in designing effective learning environments, concentrating solely upon CCK development is not sufficient. Prospective teachers also need to develop SCK that is typically not required for other professions. Curriculum materials to support college courses that develop CCK and SCK in tandem are in their beginning stages of development (e.g., Perkowski \& Perkowski, 2006), but much work remains to be done in field-testing and refining these materials. The present study, as well as other studies that have been conducted on the teaching of probability (Stohl, 2005), support the notion that the further development of such materials and accompanying courses is an important area of scholarship which needs to continue to expand greatly in the future. The qualitative descriptions provided in this report can be used to help inform such endeavors.

\section{Acknowledgement}

The research described in this report was supported with Mathematics Partnership grant funds from the Maryland State Department of Education. 


\section{References}

American Statistical Association. (2005). Guidelines for assessment and instruction in statistics education (GAISE) college report. Retrievedfrom http://www.amstat.org/education/GAISE/GAISECollege.htm.

Amir, G. S., \& Williams, J. S. (1999). Cultural influences on children's probabilistic thinking. The Journal of Mathematical Behavior, 18, 85-107. doi:10.1016/S07323123(99)00018-8

Ancker, J. S. (2006). The language of conditional probability. Journal of Statistics Education, $14(2)$.

Ball, D. L., Hill, H. C., \& Bass, H. (2005, Fall). Knowing mathematics for teaching: Who knows mathematics well enough to teach third grade, and how can we decide? American Educator, 29, 14-22.

Bright, G. W., Frierson, D. Jr., Tarr, J. E., \& Thomas, C. (2003). Navigating through probability in grades 6-8. Reston, VA: National Council of Teachers of Mathematics.

Clement, L. L., \& Bernhard, J. Z. (2005). A problem-solving alternative to using key words. Mathematics Teaching in the Middle School, 10, 360-365.

Conference Board of the Mathematical Sciences. (2001). The mathematical education of teachers. Providence, Rhode Island: American Mathematical Society.

Curcio, F. (2002). A user's guide to Japanese Lesson Study: Ideas for improving mathematics teaching. Reston, VA: National Council of Teachers of Mathematics.

Falk, R. (1986). Conditional probabilities: Insights and difficulties. In R. Davidson \& J. Swift (Eds.), Proceedings of the Second International Conference on Teaching Statistics, Victoria, B.C.: University of Victoria (pp. 292-297). Voorburg, The Netherlands: International Statistical Institute.

Franklin, C. A., Kader, G., Mewborn, D., Moreno, J., Peck, R., Perry, M., \& Scheaffer, R. (2007). Guidelines for assessment and instruction in statistics education (GAISE) report: A pre-K-12 curriculum framework. Alexandria, VA: American Statistical Association.

Glesne, C. (1999). Becoming qualitative researchers: An introduction (2 ${ }^{\text {nd }}$ ed.). New York: Longman.

Groth, R. E. (2007). Toward a conceptualization of statistical knowledge for teaching. Journal for Research in Mathematics Education, 38, 427-437.

Henningsen, M., \& Stein, M. K. (1997). Mathematical tasks and student cognition: Classroom-based factors that support and inhibit high-level mathematical thinking and reasoning. Journal for Research in Mathematics Education, 28, 524-549. doi: $10.2307 / 749690$ 
Hill, H. C., Schilling, S. G., \& Ball, D. L. (2004). Developing measures of teachers' mathematical knowledge for teaching. Elementary School Journal, 105, 11-30. doi:10.1086/428763

Jones, G. A., Langrall, C. W., \& Mooney, E. S. (2007). Research in probability: Responding to classroom realities. In F.K. Lester (Ed.), Second handbook of research on mathematics teaching and learning (pp. 909-955). Charlotte, NC: NCTM and Information Age Publishing.

Kelly, I. W., \& Zwiers, F. W. (1986, August). Introducing disjoint and independent events in probability. Paper presented at the Second International Conference on Teaching Statistics, Victoria, Canada.

Konold, C., \& Miller, C. D. (2005). TinkerPlots: Dynamic data exploration. [Computer software]. Emeryville, CA: Key Curriculum Press.

Lappan, G., Fey, J. T., Fitzgerald, W. M., Friel, S., \& Phillips, E. D. (1997). Connected mathematics: What do you expect? Menlo Park, CA: Dale Seymour Publications.

Maryland State Department of Education. (2004). Voluntary state curriculum $\begin{array}{llll}\text { mathematics } & \text { grades } & \text { Retrieved } & \text { from }\end{array}$ http://mdk12.org/share/vsc/vsc_mathematics_gr38.pdf.

Maxwell, J. A. (2005). Qualitative research design: An interactive approach. Thousand Oaks, CA: Sage.

Miles, M. B., \& Huberman, A. M. (1994). Qualitative data analysis (2nd ed.). Thousand Oaks, CA: Sage Publications.

National Center for Research in Mathematical Sciences Education \& Freudenthal Institute (Eds.). (1997-1998). Mathematics in context. Chicago, IL: Encyclopaedia Brittanica.

National Council of Teachers of Mathematics. (2000). Principles and standards for school mathematics. Reston, VA: Author.

National Research Council. (2000). How people learn: Brain, mind, experience, and school. Washington, D.C.: National Academy Press.

Perkowski, D. A., \& Perkowski, M. (2006). Data analysis and probability connections: Mathematics for middle school teachers. New York: Pearson.

Richardson, L., \& St. Pierre, E. A. (2005). Writing: A method of inquiry. In N.K. Denzin \& Y.S. Lincoln (Eds.), The Sage handbook of qualitative research ( ${ }^{\text {rd }}$ ed.) (pp. 959-978). Thousand Oaks, CA: Sage.

Russell, S. J., Schifter, D., \& Bastable, V. (2002). Developing mathematical ideas: Working with data. Parsippany, NJ: Dale Seymour Publications.

Scheaffer, R., Smith, W. B. (2007). Using statistics effectively in mathematics education research: A report from a series of workshops organized by the American Statistical Association with funding from the National Science Foundation. Alexandria, VA: American Statistical Association. 
Schoenfeld, A. H. (1992). Learning to think mathematically: Problem solving, metacognition, and sense making in mathematics. In D.A. Grouws (Ed.), Handbook of research on mathematics teaching and learning (pp. 334-370). Reston, VA: NCTM.

Schwarz, C. V., \& Gwekwerere, Y. N. (2007). Using a guided inquiry and modeling instructional framework (EIMA) to support preservice K-8 science teaching. Science Education, 91, 158-186.

Shaugnessy, J. M. (1992). Research in probability and statistics: Reflections and directions. In D.A. Grouws (Ed.), Handbook of research on mathematics teaching and learning (pp. 465-494). Reston, VA: National Council of Teachers of Mathematics.

Shaughnessy, J. M. (2003). Research on students' understandings of probability. In J. Kilpatrick, W.G. Martin, \& D. Schifter (Eds.), A research companion to Principles and standards for school mathematics (pp. 216-226). Reston, VA: NCTM.

Steffe, L. P., \& Thompson, P. W. (2000). Teaching experiment methodology: Underlying principles and essential elements. In A.E. Kelly \& R.A. Lesh (Eds.), Handbook of research design in mathematics and science education (pp. 267-306). Mahwah, NJ: Erlbaum.

Stipek, D., Salmon, J. M., Givvin, K. B., Kazemi, E., Saxe, G., \& MacGyvers, V. L. (1998). The value (and convergence) of practices suggested by motivation research and promoted by mathematics education reformers. Journal for Research in Mathematics Education, $29,465-488$.

Stohl, H. (2005). Probability in teacher education and development. In G.A. Jones (Ed.), Exploring probability in school: Challenges for teaching and learning (pp. 345-366). New York: Springer.

Tarr, J. E. (1997). Using middle school students' thinking in conditional probability and independence to inform instruction (Doctoral dissertation). Available from Dissertation \& Theses database. (Publication No. AAT 9803741).

Tarr, J. E., \& Jones, G. A. (1997). A framework for assessing middle school students' thinking in conditional probability and independence. Mathematics Education Research Journal, 9, 39-59.

Tarr, J. E., \& Lannin, J. K. (2005). How can teachers build notions of conditional probability and independence? In G.A. Jones (Ed.), Exploring probability in school: Challenges for teaching and learning (pp. 215-238). New York: Springer. doi:10.1007/0-387-24530$8 \_10$

Watson, J. M. (1995). Conditional probability: Its place in the mathematics curriculum. Mathematics Teacher, 88, 12-17.

Watson, J. M. (1997). Chance and data for luddites. Australian Mathematics Teacher, 53(3), 24-29. 
Watson, J. M. (2001). Profiling teachers' competence and confidence to teach particular mathematics topics: The case of chance and data. Journal of Mathematics Teacher Education, 4, 305-337.

Watson, J. M., \& Moritz, J. B. (2002). School students' reasoning about conjunction and conditional events. International Journal of Mathematical Education in Science and Technology, 33, 59-84.

Wood, T. (1998). Alternative patterns of communication in mathematics classes: Funneling or focusing? In H. Steinbring, M.B. Bartolini Bussi, \& A. Sierpinska (Eds.), Language and communication in the mathematics classroom (pp. 167-178). Reston, VA: National Council of Teachers of Mathematics.

\section{NOTES}

${ }^{1}$ In the U.S., the setting for the study, middle school generally consists of grades 6-8 (students who are approximately 11-14 years old). High school generally consists of grades 9-12 (14-18 year old students).

\section{Author}

Randall Groth, Department of Education Specialties, Seidel School of Education and Professional Studies, Salisbury University, USA; regroth@salisbury.edu; http://faculty.salisbury.edu/ regroth/ 